\author{
Alina V. Pustovaya \\ National Research Tomsk State University, \\ Tomsk, Russia \\ Evgenia N. Pustovaya \\ Neuropsychologist of Psychological \\ and Defectological Center 'World of Family' \\ Novosibirsk, Russia
}

\title{
Neuropsychological indicators of the level of formation of higher mental functions in children with autism spectrum disorders
}

Abstract: This article presents the results of neuropsychological diagnostics of a group of children with autism spectrum disorders.

Keywords: autism spectrum disorders, neuropsychology, neuropsychological diagnostics, higher mental functions.

Introduction. The relevance of the study is associated with the increase in the registration of cases of autistic disorders among the child population. According to the World Health Organization, as of November 2019, one child out of 160 has an autistic spectrum disorder (ASD) [1]. Thus, our research focuses on neuropsychological indicators of the level of formation of higher mental functions in children with ASD.

According to the $10^{\text {th }}$ Revision (ICD-10) of the International Statistical Classification of Diseases and Related Health Problems, autistic disorders are general developmental disorders and represent a group of disorders characterized by qualitative deviations in social interactions and indicators of sociability as well as a limited, stereotypical, repetitive set of interests and actions [2]. The neuropsychological approach to the problem of autism is aimed at understanding the connection between the functioning of the brain of autistic children with mental processes, cognitive activity, behavior, and speech. Finding the level of formation of higher mental functions in children with ASD is one of the most important stages of neuropsychological examination. Based on the identified developmental disorders, specialists can choose the most effective rehabilitation route. 
Materials and methods. For the study, a group of 49 children (13 girls and 36 boys) aged 7-15 with ASD (diagnoses according to ICD-10: F84.0, F84.1, F84.5) was selected. Neuropsychological examination of these children was performed by using the method of neuropsychological diagnostics of J. M. Glozman et al. [3, 4], which includes assessment of social, cognitive, motor, neurodynamic and regulatory development. Neuropsychological examination of children includes the following: establishing contact with the child; the stage of examination, which takes place at the table and, if necessary, involves various game test tasks (in cases when the child is allowed to sit at the table for the prescribed age, you can continue the examination while standing at the table); a pause for rest if the child shows signs of fatigue; final conversation aimed at raising parents ' awareness of the child's problems and their causes (by joint analysis of the questionnaire filled in by parents) and probabilistic forecasts of the child's development [1,2]. Mathematical data processing was performed using ANOVA.

Results. The children showed differences in the level of formation of higher mental functions in accordance with clinical diagnoses. For children diagnosed with F84.0, the most problematic areas are cognitive $(\mathrm{F}=2.7, \mathrm{p}<0.01)$ and neurodynamic and regulatory development $(\mathrm{F}=4.7, \mathrm{p}<0.01)$. For children with a diagnosis of F84.1, the most problematic is the sphere of motor development $(\mathrm{F}=07, \mathrm{p}<0.01)$. For those with a diagnosis of F84.5, the most problematic is the sphere of social development $(\mathrm{F}=0.4, \mathrm{p}<0.01)$. The problem area for all groups of children is speech development, in particular, many children cannot master speech as a means of communication or use speech as a means of meeting their needs.

Conclusion. For the surveyed group of children, the least formed tends to be the sphere of social development $(\mathrm{F}=9.07, \mathrm{p}<0.01)$, which is one of the main characteristics of the manifestation of autistic disorders. The most formed is the sphere of motor development $(\mathrm{F}=11.04$, $\mathrm{p}<0.01)$. It is worth noting the main difficulties encountered during the neuropsychological examination of children with autism spectrum disorders: (1) holding the working position throughout the entire period of the diagnostic examination; (2) difficulties in dialogue due to the fact that many children cannot master speech as a means of communication 
or use speech as a means of meeting their needs, (3) isolated hysterical manifestations and symptoms of negativism and impulsivity.

1. Rasstrojstva autisticheskogo spektra (RAS) // Vsemirnaya organizaciya zdravoohreniya URL: https://www.who.int/ru/news-room/fact-sheets/detail/ autism-spectrum-disorders (date of the application: 02.08.2020).

2. International classification of diseases ( $10^{\text {th }}$ revision $)$. Classification of mental and behavioral disorders. SPb, 1994.

3. Glozman J.M., Soboleva A. E. Nejropsihologicheskaya diagnostika detej shkol'nogo vozrasta. M.: Artoprint, 2014

4. Glozman J. M., Soboleva A. E., Titova Yu. O. Nejropsihologicheskaya diagnostika detej doshkol'nogo vozrasta. M. : AJRIS-PRESS, 2019. 